\title{
Transferência do conhecimento tecnológico gerado em projetos de P\&D no setor elétrico brasileiro: o caso Eletronorte
}

\author{
The transfer of technological knowledge generated in $R \& D$ projects in brazilian \\ electrical sector: the case of Eletronorte
}

\begin{abstract}
Maria Zuleila Carmona Regino Campos zuleila@cemig.com.br Profissional Mestre em Administração da Companhia Energética de Minas Gerais - CEMIG

Marta Araújo Tavares Ferreira marta.araujo@pucminas.br

Professora do Programa de Pós-graduação em Administração da Pontifícia Universidade Católica de Minas Gerais

Sandro Márcio da Silva sandromarcio@pucminas.br

Professor do Departamento de Administração do Instituto de Ciências Econômicas e Gerenciais da PUC Minas
\end{abstract}

Editor Científico Responsável: Prof. Dr. Tales Andreassi Prof. do Departamento de Administração Geral e Recursos Humanos da Escola de Administração de São Paulo da Fundação Getúlio Vargas - EAESP/FGV

Recebido em: 03 de março de 2009 Aprovado em: 11 de novembro de 2009

\begin{abstract}
Resumo
Neste trabalho apresenta-se o estudo de caso de uma empresa do setor elétrico, tendo como objetivo analisar as ações implementadas para a transferência e disseminação do conhecimento tecnológico gerado em seus projetos de pesquisa e desenvolvimento. As principais fontes de coleta de dados foram entrevistas com os gestores da empresa, documentos fornecidos e pesquisas no site da empresa. A empresa analisada tem como finalidade principal a realização de estudos, projetos, construção e operação de usinas geradoras e de sistemas de transmissão e distribuição de energia elétrica, além da comercialização da energia gerada. Conclui-se que o processo de disseminação e transferência do conhecimento tecnológico na empresa encontra-se bem implantado pela adoção de múltiplas práticas de compartilhamento do conhecimento, bem como pela concepção de um modelo próprio para gerir a inovação. Esta exerce papel fundamental na definição das diretrizes estratégicas da empresa, originando-se em seu ambiente e mobilizando equipes multidisciplinares para gerar soluções e novas ideias. A extensão da pesquisa até o ponto de comercialização e a formalização de papéis no processo de inovação foram consideradas os pontos fortes do modelo de transferência da empresa em estudo.
\end{abstract}

Palavras-chave: Transferência de tecnologia. Compartilhamento de conhecimento. Relação universidade-empresa. Transferência de P\&D. Setor elétrico brasileiro. 


\section{Abstract}

This paper presents a case study in the Brazilian electrical sector and aims at analyzing the procedures implemented to support the transfer and dissemination of technological knowledge generated through R\&D. The main sources of data were interviews with firm managers, documents and the firm website. The studied enterprise has as main goals to project, construct and operate electricity generation plants and electricity transmission and distribution systems, and to commercialize electricity. The paper concludes that technological knowledge dissemination and transfer process is firmly implemented in the firm by the adoption of multiple practices of knowledge sharing, as well as by the conception of a specific model to manage innovation. In fact, innovation plays a fundamental role in the definition of the firm strategic guidelines and mobilizes multidisciplinary and inter-organizational teams. The extension of R\&D projects up to the point of commercialization and the formalization of roles in the innovation process were considered the strengths of the transfer model of the studied firm.

Key-words: Technology transfer. Knowledge sharing. University-enterprise cooperation. R\&D transfer. Brazilian electrical sector. 
A reestruturação do setor elétrico no Brasil consolidou um novo modelo empresarial, reduzindo as barreiras legais e institucionais a novos entrantes, ao mesmo tempo em que se viram aumentadas e diversificadas a concorrência dos fornecedores, a capacidade de negociação dos consumidores e a oferta de produtos substitutos da energia elétrica. Nesse contexto, as empresas de energia elétrica procuram abrir diferentes alternativas de negócios, a partir do desenvolvimento de novos produtos e serviços.

Com vistas a incentivar a busca constante por inovações e fazer frente aos desafios tecnológicos do setor elétrico, foi regulamentada pelo Governo Federal a obrigatoriedade do desenvolvimento de Programas Anuais de Pesquisa e Desenvolvimento (P\&D) pelas empresas do setor. As concessionárias e permissionárias de distribuição, geração e transmissão de energia elétrica devem aplicar anualmente um percentual mínimo de sua receita operacional líquida no Programa de Pesquisa e Desenvolvimento do Setor de Energia Elétrica, cabendo à ANEEL regulamentar o investimento no programa, avaliar e aprovar as condições para a execução das pesquisas e acompanhar seus resultados.

A disseminação e a transferência do conhecimento tecnológico gerado nesses projetos de pesquisa e desenvolvimento representam grande oportunidade de geração de novos negócios e de ganho de eficiência e competitividade pelas empresas do setor.

Neste artigo apresenta-se o estudo de caso de uma empresa do setor elétrico, tendo como objetivo analisar as ações implantadas para a transferência e disseminação do conhecimento tecnológico gerado em seus projetos de pesquisa e desenvolvimento.

\section{COMPARTILHAMENTO E TRANSFERÊNCIA DO CONHECIMENTO NA ORGANIZAÇÃO}

A transferência do conhecimento tem sido o principal gargalo no processo de gestão do conhecimento, uma vez que diversos elementos determinantes estão enraizados em pessoas ou locais específicos. Além disso, a contínua busca pela melhor forma de explicitar o conhecimento reforça a necessidade da criação de um ambiente de transmissão baseado na confiança tanto entre as pessoas como das pessoas em relação à empresa. A codificação do 
conhecimento ou construção da memória visa a organizá-lo de forma a disponibilizá-lo para a organização como um todo, favorecendo o processo de inovação.

Davenport e Prusak (1999) evidenciam a necessidade de se ter uma estrutura técnica e organizacional adequada, uma estrutura de conhecimento padrão flexível (equilíbrio entre a necessidade de flexibilidade - porque o conhecimento muda - e a padronização, para que possa ser utilizado por diversas pessoas) e múltiplos canais para a transferência do conhecimento. Também Fleury e Oliveira Jr. (2001) lembram que, desde que a organização esteja empenhada em criar, transferir, disseminar e aplicar o conhecimento, terá de se adaptar a uma nova formatação. Para tanto, necessita codificar e simplificar o conhecimento dos indivíduos e dos grupos e torná-lo acessível a todos.

Grandes empresas possivelmente têm mais dificuldade em disponibilizar e disseminar conhecimentos, em razão da estrutura hierárquica ainda predominante e do grande número de empregados, o que exigirá delas, além de estrutura de tecnologia da informação mais consistente, mudanças comportamentais e culturais. Além disso, é necessário repensar o processo de circulação do conhecimento para que ele possa ser realmente compartilhado.

Nonaka e Takeuchi (1997) destacam a importância da disseminação do conhecimento como atividade central da empresa, processo que deve ser realizado continuamente em todos os níveis da organização. O conhecimento é interpretado de acordo com a perspectiva pessoal de quem o recebe, sendo então necessária para a utilização do conhecimento disseminado uma direção comum que deve ser dada pela gerência.

Contrariamente, Davenport e Prusak (1999) acreditam que a transferência do conhecimento se dá independentemente de ser um processo gerenciado. A forma mais efetiva de disseminação e transferência do conhecimento é a informalidade, um mecanismo que sobrecarrega de trabalho principalmente as pessoas mais brilhantes, deixando-lhes pouco tempo para pensar ou conversar. A melhor estratégia de transmissão do conhecimento consiste em descobrir maneiras eficazes de permitir que os indivíduos conversem e escutem o que se tem a dizer.

Nonaka e Takeuchi (1997) e Davenport e Prusak (1999) apontam a dificuldade de se transferir conhecimento tácito da fonte de criação para o restante da empresa. Esses autores acreditam que a transferência dessa forma de conhecimento somente se efetiva de forma espontânea e não estruturada nas conversas informais. Nesse aspecto, passeios técnicos, participação em congressos e feiras podem constituir boa alternativa para estimular o compartilhamento de conhecimentos tácitos. Também o rodízio de profissionais é considerado 
boa prática, já que permite aos indivíduos tanto absorver novos conhecimentos como transferir aqueles que detêm.

Outros aspectos que favorecem ou dificultam a disseminação do conhecimento são a cultura, que inclui os valores das pessoas e da empresa, a estrutura organizacional e a tecnologia, especialmente para disseminação do conhecimento explícito. Entre os fatores que podem inibir o fluxo de conhecimento na empresa, encontra-se a concentração do conhecimento em uma única pessoa. Assim, a troca de informações deve ser constantemente estimulada pelos gestores, tanto formal como informalmente.

Dessa forma, as práticas e políticas devem servir de apoio à criação, armazenamento e compartilhamento do conhecimento; à aprendizagem - necessidade de contínuo aprendizado como forma de fazer frente às mudanças macro e microambientais; aos modelos mentais ideias profundamente enraizadas que interferem e moldam os atos e decisões das pessoas, sendo necessário um processo de contínua reflexão, criação e recriação desses modelos, resultando em verdadeiros processos de desaprendizagem e aprendizagem. As pessoas devem estar voltadas para a disseminação do conhecimento, partilhando experiências e ideias (ANGELONI, 1999).

\section{INOVAÇÃO E TRANSFERÊNCIA TECNOLÓGICA NA ORGANIZAÇÃO}

O processo de transferência do conhecimento tecnológico envolve toda a infraestrutura necessária ao adequado fluxo das informações. Deve possibilitar a transferência do conhecimento das pessoas, suas capacidades e competências, assim como o conhecimento incorporado em produtos e serviços, documentos técnicos e científicos e práticas organizacionais. Nesse processo, além de se considerarem todos os elementos envolvidos, considera-se também o aprendizado gerado no desenvolvimento da tecnologia que estiver sendo transferida.

A tecnologia e o conhecimento tecnológico são instrumentos essenciais para a construção do desenvolvimento, em termos de produção de riqueza, poder e domínio da natureza, uma vez que a tecnologia é criada pelo homem para satisfazer suas necessidades.

A inovação, por sua vez, nem sempre se refere a uma nova tecnologia ou invenção, mas diz respeito muito mais à percepção das pessoas, empresas ou sistema social da novidade, 
PUC Minas

como um produto ou processo que está sendo usado pela primeira vez, independentemente do fato de esse produto ou processo ser novo ou velho (SPENCE, 1994).

O processo de inovação tecnológica abrange uma série de atividades que vão desde a geração de ideias, passando pelo desenvolvimento, chegando às aplicações práticas. Nesse contexto, a transferência tecnológica entre organizações ou indivíduos constitui parte importante do processo, especialmente quando se pretende transformar conhecimentos em produtos competitivos.

O processo de inovação tecnológica inicia-se a partir da geração de ideias, seguindo-se a aplicação prática dessas ideias. O resultado dessa prática deve ou não ser transferido a outras pessoas ou aos demais setores cujas atividades o exijam, ou mesmo entre organizações, especialmente se o objetivo for transformar conhecimentos em produtos e processos com vistas à competitividade da empresa. A transferência entre setores e organizações considera tanto os aspectos de eficácia como outros relativos à estratégia empresarial (SANDIA NATIONAL LABORATORIES, 1999). Tecnologia e conhecimento tecnológico se tornaram então componentes essenciais de desenvolvimento empresarial, capazes de assegurar competitividade e sustentabilidade às organizações.

O processo de inovação tecnológica é complexo, dinâmico e dependente da capacidade dos agentes e relaciona-se com a aplicação de novos conhecimentos desenvolvidos muitas vezes em atividades de P\&D. A pesquisa e o desenvolvimento cobrem uma gama de atividades que vão desde a busca de conhecimentos de pouca aplicabilidade até o desenvolvimento de produtos e serviços, funcionando como suporte ao processo de inovação tecnológica nas empresas. Via de regra, os projetos de $\mathrm{P} \& \mathrm{D}$ têm por objetivo a busca de conhecimentos sobre determinado produto ou processo e são desenvolvidos em parceria entre instituições tecnológicas geradoras de conhecimento e empresas que custeiam e executam partes dos projetos, visando aperfeiçoar os investimentos em P\&D e Engenharia pelo compartilhamento de recursos.

A literatura registra mudanças contínuas na gestão do processo de inovação desde 1950, quando a inovação era essencialmente gerada pelos departamentos de $\mathrm{P} \& \mathrm{D}$, no chamado modelo linear; as necessidades de mercado foram enfatizadas nos anos 60, motivando projetos de P\&D para gerar inovações. Esse movimento seguiu em direção a uma abordagem mais equilibrada entre necessidades de mercado e oferta tecnológica, conhecido como modelo interativo. Hoje, todas as tendências levam a um sistema integrado em redes de cooperação entre os diversos atores internos e externos às organizações, como fornecedores, 
PUC Minas

clientes e instituições de ensino e pesquisa. Esse novo modelo parece ter impacto positivo sobre o processo de inovação, trazendo conhecimento compartilhado e complementaridade.

Na visão de Rebentish e Ferreti (1993), a transferência tecnológica consiste no desenvolvimento comercial, pelo setor privado, de um novo conhecimento ou tecnologia gerada em laboratórios de centros de pesquisa ou universidades.

Atualmente, o intercâmbio de ideias, habilidades e conhecimento tácito gerados pela pesquisa vem sendo cada vez mais enfatizado. Nesse caso, a transferência tecnológica compreenderá, além do próprio produto ou processo final, o conhecimento sobre todos os novos descobrimentos e atividades desenvolvidas. Esse modelo pressupõe a transferência da combinação dos conhecimentos tácito, prático e explícito.

A transferência tecnológica a partir de centros de pesquisa e universidades para o setor empresarial é processo complexo que depende diretamente de diversos profissionais das organizações envolvidas, compreendendo um número significativo de atividades, entre as quais talvez a principal delas seja a implementação e o uso sistemático de sistemas de informação. A transferência não deve ser um processo unidirecional nem realizar-se somente durante determinado tempo. Pelo contrário, ele deve ser interativo, como uma contínua atividade de pesquisa estruturada pelo conhecimento tecnológico (PLONSKY, 1990).

Davenport e Prusak (1999) sinalizam algumas dificuldades detectadas pelas equipes de P\&D para transferir conhecimentos. A primeira delas diz respeito à localização da área em que determinado conhecimento será utilizado efetivamente. Os autores ressaltam que, pelo fato de as pesquisas serem conduzidas em "laboratórios", até mesmo a diferença de linguagem entre os técnicos e os clientes constitui um dificultador no processo de transferência.

O processo de transferência tecnológica corresponde a uma soma de atividades que incluem a transferência ou troca de informações científicas, tecnológicas e comerciais que pode resultar na criação de novas técnicas, produtos e serviços. Essa transferência pode ser facilitada por recursos de tecnologia da informação, como internet, redes corporativas, correios eletrônicos e blogs, entre outros, além das variadas possibilidades de interação pela via informal, reconhecida pela grande maioria dos autores como a principal e mais efetiva via para a transferência de conhecimentos tácitos.

Faulkner (1994) ressalta que a transferência de tecnologia corresponde à transferência de uma combinação de conhecimentos tácitos, práticos e codificados, essencial ao processo de inovação. Já Grant e Steele (1995) apontam que o processo de inovação requer tomada de 
decisão relativa à seleção e transferência da tecnologia tangível, bem como do conhecimento tácito e da informação científica e tecnológica, exigindo tratamento específico nas fases de seleção, organização, acesso e uso da informação, utilizando-se para isso de plataformas de coleta e disseminação, como canais de transferência que permitam interação contínua dos diversos usuários.

\section{APRESENTAÇÃO E DISCUSSÃO DO CASO}

A Eletronorte é uma subsidiária da Eletrobrás, oficialmente instituída em 20 de julho de 1973, com atuação nos estados da região Norte, e cujo negócio principal é a geração, transmissão e comercialização de energia elétrica.

Como todas as empresas do setor elétrico, a Eletronorte sofreu reestruturações decorrentes da nova regulamentação do setor. Por essa razão, ela tem aplicado práticas arrojadas de gestão, tornando sua estrutura organizacional mais enxuta.

A Eletronorte possui hoje estrutura organizacional composta de quatro diretorias e uma presidência, a saber: Diretoria de Engenharia, Diretoria Econômico-financeira, Diretoria de Produção e Comercialização e Diretoria de Gestão Corporativa, cabendo a esta última a gestão de pessoal, à qual se submete a Superintendência de Suporte à Gestão do Conhecimento.

\subsection{Metodologia}

Optou-se pelo estudo de caso único, em que a unidade de análise é uma concessionária de energia elétrica, na qual se procurou conhecer o processo de disseminação e transferência do conhecimento tecnológico oriundo de projetos de P\&D. Essa concessionária foi escolhida para estudo por apresentar o mais avançado sistema de gestão do processo de transferência entre as concessionárias brasileiras, de acordo com os resultados de pesquisa preliminar.

Para a coleta de dados, as fontes de evidência utilizadas foram o levantamento documental e bibliográfico, observação e entrevistas. 
As entrevistas foram realizadas com três integrantes-chave das equipes de inovação da

Eletronorte: o Superintendente de Desenvolvimento e Educação Empresarial e Gerente de Suporte à Gestão do Conhecimento, o Gerente de Coordenação dos Programas de Pesquisa e Desenvolvimento Tecnológico da Eletronorte, além da Gerente de Articulação com a Indústria Nacional. Buscou-se transcrever com clareza e objetividade as anotações realizadas durante as entrevistas, ordenando as informações de forma lógica para a redação do estudo de caso.

De acordo com os objetivos estabelecidos para este estudo, os dados obtidos foram tratados de forma qualitativa e a análise teve como referência a revisão bibliográfica.

Como limitações e dificuldades, deve-se destacar o fato de não terem sido entrevistados usuários dos resultados de projetos de $\mathrm{P} \& \mathrm{D}$ ou gerentes de projetos de $\mathrm{P} \& \mathrm{D}$. Além disso, é preciso ter em mente que as variáveis pesquisadas, mesmo significativas, podem não esgotar as possibilidades do tema em questão.

\subsection{Gestão do conhecimento na Eletronorte}

A gestão do conhecimento na Eletronorte pode ser considerada um processo em plena consolidação. A empresa avança na sistematização das diversas práticas e programas já implantados, destacando-se o ensino à distância, a Universidade Corporativa da Eletronorte (UCEL), a televisão digital educativa, o portal da UCEL, que divulga sistematicamente as monografias e teses de autoria dos empregados ou que dizem respeito à empresa, o Programa Eletronorte de Propriedade Intelectual, o Programa Eletronorte de Pesquisa e Desenvolvimento, a biblioteca, a intranet, a gestão da rede corporativa de tecnologia da informação e o sistema de gestão documental. Além disso, a empresa trabalha no estímulo à multiplicação interna de conhecimento.

A Eletronorte se organizou estruturalmente para implantar seu sistema de GC por meio da criação de uma área específica ligada à Gerência Executiva, na Diretoria de Gestão Corporativa, e à Superintendência de Desenvolvimento e Educação Empresarial. Suas principais atribuições envolvem o controle e a normatização da produção e $\mathrm{o}$ compartilhamento do conhecimento técnico e científico da empresa, do conhecimento gerado nos projetos de pesquisa e desenvolvimento - relatórios, metodologias e protótipos - bem 
como das melhorias e inovações de processos operacionais, com base em normas técnicas e manuais. Além disso, a mesma gerência coordena o registro de patentes e de softwares, as melhorias de equipamentos e as inovações tecnológicas.

Como a maioria das organizações, a Eletronorte delineou seu processo de GC com a implantação de práticas do programa de Qualidade Total e, a partir de 1997, com a adoção do modelo de gestão com base nos critérios de excelência da Fundação Prêmio Nacional de Qualidade (FPNQ). No contexto desse programa, a concessionária implantou a metodologia do Gerenciamento pelas Diretrizes.

A UCEL, uma das primeiras iniciativas para gerir o conhecimento organizacional, baseia-se no uso de tecnologias interativas, como a internet e a videoconferência, para mediar suas relações de ensino e aprendizagem em toda a área de atuação da empresa. Já a intranet da Eletronorte constitui seu principal repositório de conteúdos, que vão desde a troca virtual de saberes até a publicação das melhores práticas, sendo um importante instrumento de consolidação do conhecimento publicado, negociado e aplicado na empresa.

\subsection{Compartilhamento, disseminação e transferência do conhecimento na Eletronorte}

Um dos mais reconhecidos instrumentos de disseminação do conhecimento na empresa é a UCEL. No ambiente da Universidade Corporativa, a Eletronorte desenvolve um programa de estímulo ao compartilhamento com base em um instrumento denominado "lição ponto a ponto". As lições são apresentadas em formato predeterminado, que permite o registro do conhecimento, do mais simples ao mais sofisticado, como a operação de máquinas nas usinas. A meta é estimular os empregados a publicarem na intranet o conhecimento que julgam importante compartilhar.

Na UCEL, as tecnologias são instrumento de grande importância, na medida em que ligam todos os membros da empresa entre si e criam uma memória institucional acessível a todos. Além disso, os sistemas de informação são integrados e inteligentes, de forma a apoiar a colaboração de todos os empregados.

No que diz respeito à valorização das iniciativas do compartilhamento de conhecimento, desde 1995 a empresa identifica os esforços de seus colaboradores voltados para a busca de melhoria de resultados, por meio da implementação do Painel Integrado da 
Qualidade (PIQ), no qual as pessoas relatam suas experiências. Realizado anualmente, o Painel é realizado em diferentes localidades, visando alcançar o maior número possível de empregados, levando em conta a dispersão geográfica que caracteriza a Eletronorte. O PIQ tem sido responsável pela revelação de grandes ideias, soluções e talentos.

Mais recentemente, foram instituídos o Prêmio Muiraquitã de Inovação Tecnológica da Eletronorte e a Feira de Inovação Tecnológica. Essas iniciativas visam a estimular a cultura de inovação e a buscar parcerias para industrializar as inovações da empresa.

A maioria dos projetos vencedores do Prêmio Muiraquitã foi desenvolvida por trabalhadores de "chão de fábrica", que vivenciam os problemas da operação e manutenção nas instalações da Eletronorte. O prêmio contempla as categorias produto, relacionadas à inovação de bens e serviços produzidos, e as de processo, estando divididas nas modalidades de inovações de colaboradores e inovações de projetos de P\&D.

Os trabalhos são classificados em três faixas de pontuação: ouro, prata e bronze, que recebem, além do troféu de participação concedido a todos os participantes, prêmios financeiros. Os trabalhos são julgados por comissões formadas por empregados indicados pelas diretorias e presidência da Eletronorte.

Com a realização da Feira de Inovação Tecnológica, cria-se uma oportunidade de comercializar essas inovações por meio da transferência de tecnologia ou da exploração de patentes.

O Programa de Propriedade Intelectual da Eletronorte destina até 20\% dos lucros resultantes da comercialização de patentes aos funcionários que compartilham seus inventos com a empresa. Os primeiros contratos de co-titularidade de patentes foram assinados em 2007.

Iniciativas como o Prêmio Muiraquitã já trouxeram bons resultados para a empresa. Como exemplo, pode-se citar o bico injetor de soluções químicas para tratamento de água em tubulação de sistemas de resfriamento de máquinas de grande porte, desenvolvido pela Regional de Tucuruí, que resultou em uma economia de $\mathrm{R} \$ 917$ mil por parada de unidade geradora. No total, os produtos inovadores desenvolvidos pelos colaboradores da empresa já geraram economia de mais de R\$43 milhões, até 2007.

Boa parte do conhecimento criado na empresa já se encontra formalizada em manuais e normas de procedimento, e muitos desses conhecimentos se desenvolveram a partir das iniciativas premiadas nas edições do PIQ, do Prêmio Muiraquitã e da Feira de Inovação Tecnológica. Esses manuais e normas constituem novos instrumentos de compartilhamento 
do conhecimento, além da intranet, das comunidades virtuais, dos fóruns de discussão e da troca de experiências por ocasião dos eventos, pelo contato informal entre os vários colaboradores da Eletronorte.

Constituem também importantes instrumentos para a disseminação e transferência do conhecimento na Eletronorte as redes de tecnologia formadas para a elaboração do Programa Anual de Pesquisa e Desenvolvimento Tecnológico. Elas envolvem tanto os colaboradores internos das diferentes unidades como os parceiros externos oriundos das Universidades da região, além dos gerentes e coordenadores de projetos e o próprio Comitê Gestor de Pesquisa e Desenvolvimento Tecnológico e Inovação. Essas redes permitem um contato permanente entre seus membros por meios virtuais, embora não estejam excluídas as reuniões presenciais, que são realizadas sempre que necessário.

Em relação ao registro do conhecimento, deve-se assinalar a edição de livros, uma vasta produção de artigos técnicos e científicos, a solução de problemas operacionais registrada em normas organizacionais e de procedimento.

A transferência do conhecimento, além dos meios citados, também se dá por intermédio de cursos e treinamentos oferecidos aos técnicos da empresa pelas instituições parceiras. Também os resultados de projetos concluídos são apresentados na Feira Tecnológica, no PIQ, nos fóruns virtuais e em encontros informais dos colaboradores.

\subsection{Gestão da inovação na Eletronorte}

O advento da Lei n. 9.991/2000, complementada pela Lei n. 10.848/2004, introduziu no setor elétrico brasileiro a obrigatoriedade de investir anualmente pelo menos $1 \%$ da receita operacional líquida (ROL) em projetos de pesquisa e desenvolvimento tecnológico (P\&D). Desse montante, $0,4 \%$ destina-se ao investimento direto das empresas, $0,4 \%$ é recolhido ao Fundo Setorial de Energia (CT-Energ), componente do FNDCT, e o restante 0,2\% é repassado para a Empresa de Pesquisa Energética (EPE). O Programa Anual de P\&D das empresas é submetido à aprovação da ANEEL e executado também sob fiscalização da Agência.

Todas as concessionárias de energia elétrica viram-se então na iminência de estruturarem-se para atenderem à legislação. Mas, apesar da existência de ferramentas, 
aplicativos e critérios específicos definidos pela ANEEL para elaboração dos Programas Anuais de $\mathrm{P} \& \mathrm{D}$, bem como prazos e regras de operacionalização dos investimentos, nos primeiros ciclos a gestão dos programas e projetos deu-se de forma bastante precária (ANEEL, 2001). Não estavam identificados à época os conhecimentos e as habilidades necessários para o gerenciamento da tecnologia e inovação nas empresas.

Ainda assim, o Programa Anual de P\&D da Eletronorte trouxe de imediato alguns resultados importantes, como solução de problemas empresariais críticos, redução de custos, aumento em 10 vezes do número de titulações (graduação, pós-graduação, mestrado e doutorado), aumento das inserções tecnológica, elétrica e social na Amazônia e crescimento do volume de recursos destinados à pesquisa.

Em fase posterior, a Eletronorte identificou, no requisito legal, um interessante mecanismo para o provimento de soluções tecnológicas críticas a seus processos. Daí a criação de um primeiro processo específico para o gerenciamento dos projetos e programas o processo de Gestão de Tecnologia e Inovação (GTI) - desenvolvido com o apoio de consultoria externa. Nele, a lógica de produção de soluções para atendimento das demandas tecnológicas identificadas nos processos empresariais começava pelo desenvolvimento de um projeto de $\mathrm{P} \& \mathrm{D}$ que, ao produzir o resultado esperado, era aprimorado com a finalidade de exploração comercial. Esse modelo tinha então como fundamento a gestão tanto do programa de $P \& D$ como da inovação, em uma cadeia que se iniciava na concepção do projeto de $P \& D$, passando pelo desenvolvimento de protótipos e produtos acabados para comercialização no mercado.

Para adequar-se ao modelo adotado, a Eletronorte alterou sua arquitetura organizacional, instituindo a Superintendência de Pesquisa e Desenvolvimento Tecnológico (GPD), compreendendo a Gerência de Coordenação dos Programas de P\&D (GPDC, responsável por elaborar e implementar o programa corporativo de P\&D de cada ciclo, atendendo ao bloco inicial da cadeia que propõe a obtenção da melhoria ou inovação a partir de projetos de P\&D) e a Gerência de Articulação com a Indústria (GPDA, responsável pela gestão de toda a propriedade intelectual produzida na empresa, além do aprimoramento do protótipo a fim de levá-lo à comercialização por meio de parcerias com a indústria). $\mathrm{O}$ principal instrumento criado pela GPDA para operacionalizar a gestão da propriedade foi o Programa Eletronorte de Propriedade Intelectual (PEPI), que, além de gerenciar todo o processo de proteção formal junto ao Instituto Nacional de Produtos Industrializados (INPI), 
ainda implementa os contratos de transferência de tecnologia para parceiros industriais, viabilizando a produção comercial da solução tecnológica desenvolvida.

\subsection{Programa de pesquisa e desenvolvimento tecnológico na Eletronorte}

Considerando as diretrizes estabelecidas em 2004 pela Política Industrial e Tecnológica do Governo Federal para promoção da autonomia tecnológica do País, visando ao aumento da produção e exportação (Lei n. 10.973 de 2004), a Eletronorte decidiu investir, de maneira mais incisiva e organizada, no desenvolvimento de novas tecnologias. Dessa forma, estaria tanto cumprindo uma obrigação legal como promover a inovação necessária ao crescimento empresarial sustentável.

O programa de Pesquisa e Desenvolvimento passou então a ser considerado uma grande oportunidade de melhoria de processos, redução de custos e até mesmo aumento das receitas decorrentes da comercialização de produtos desenvolvidos no âmbito dos projetos de P\&D.

A Superintendência de Pesquisa e Desenvolvimento Tecnológico (GPD) foi criada com o objetivo de coordenar, integrar e dinamizar as ações corporativas para o desenvolvimento tecnológico da Eletronorte. Para tanto, foi implantado um Sistema de Gestão de Tecnologia e Inovação (SGTI), que se viabilizou com a criação de um Comitê Gestor (CGPDI). Esse comitê, formado por dois representantes de cada diretoria da empresa, possui caráter formal e poder decisório Trata-se de um fórum estratégico, corporativo e formal, orientador do macroprocesso e responsável pela promoção da gestão participativa, de forma a facilitar o compartilhamento de informações, a disseminação das ações tomadas e o comprometimento dos integrantes.

A Rede Eletronorte de Tecnologia (RET) é formada pelos coordenadores locais de P\&D e pelos gerentes de projetos de P\&D. Os coordenadores locais estão lotados nas várias unidades e são capacitados para atuarem no programa. Já os gerentes de projeto são os responsáveis pela interação com as instituições de pesquisa e universidades parceiras da Eletronorte nos projetos e são geralmente especialistas no tema em desenvolvimento. A rede conta com a participação de representantes de todas as suas unidades e integrantes de 
universidades, fundações e instituições de ensino e pesquisa, o que potencializa o envolvimento das várias partes, além de permitir a inserção tecnológica das instituições da região Amazônica, de seus pesquisadores e bolsistas.

O estabelecimento dessa Rede possibilitou descentralizar todo o processo, de forma a alcançar todas as unidades da empresa e a garantir a participação efetiva das áreas operacionais desde a etapa inicial até a conclusão dos projetos. A primeira etapa corresponde ao levantamento das necessidades de $\mathrm{P} \& \mathrm{D}$, e a última à avaliação do projeto concluído, passando pela priorização dos projetos a serem executados.

As diretrizes definidas pelo CGDI (Comitê Gestor de Pesquisa, Desenvolvimento e Inovação) subsidiam a elaboração de critérios e da sistemática de avaliação e priorização de projetos de P\&D.

O ciclo de elaboração do programa de $\mathrm{P} \& \mathrm{D}$ inicia-se com o levantamento de necessidades através de um sistema alocado na intranet da empresa, que possibilita a participação de empregados em todas as unidades. Nessa etapa são levantados os problemas considerados críticos nos processos organizacionais. Entretanto é possível também expor ideias passíveis de se tornarem inovações.

Na segunda fase, todas essas informações são disponibilizadas aos potenciais parceiros externos de todo o Brasil. Na região Amazônica, especificamente, são realizados workshops com o objetivo de estimular a participação das instituições de ensino e pesquisa locais. Esse estímulo compreende até mesmo a realização de cursos intensivos de elaboração de projetos no padrão ANEEL, agência reguladora que fiscaliza o programa de $\mathrm{P} \& \mathrm{D}$ em seus aspectos legais.

\section{PRINCIPAIS RESULTADOS ALCANÇADOS}

A estruturação e a padronização do programa de $\mathrm{P} \& \mathrm{D}$ da empresa contribuíram para aperfeiçoar outros processos corporativos e já produziram resultados expressivos para a Eletronorte, como a estruturação da Gestão Tecnológica, a duplicação do volume de investimentos em $\mathrm{P} \& \mathrm{D}$ e, principalmente, a incorporação da variável tecnológica no planejamento estratégico da empresa, com diretrizes específicas nesse sentido.

Outro resultado contabilizado diz respeito ao aumento da participação de profissionais da empresa no processo de $\mathrm{P} \& \mathrm{D}$, contribuindo para alterar a cultura e o clima 
organizacionais. Além desse, destaca-se maior inserção tecnológica e social possibilitada às instituições de ensino e pesquisa da região Amazônica, por meio da participação de estudantes e pesquisadores no desenvolvimento de projetos de pesquisa. Desde o início da implementação dos programas anuais de $\mathrm{P} \& \mathrm{D}$ até 2007, a participação de pesquisadores nos workshops promovidos pela empresa aumentou em $576 \%$.

No aspecto social, o programa de P\&D da Eletronorte gera, em média, 10 empregos em cada projeto desenvolvido, entre pesquisadores e bolsistas.

Para a empresa, os resultados se refletem positivamente no retorno dos investimentos em $\mathrm{P} \& \mathrm{D}$, contabilizado a partir da utilização dos produtos e metodologias resultantes dos projetos em seus processos produtivos. Destaca-se o fato de ainda não terem sido computados os resultados decorrentes da replicação interna da tecnologia por diferentes unidades.

Também no próprio processo de gestão de $\mathrm{P} \& \mathrm{D}$, registra-se aumento da eficácia das ações implementadas, o que se evidencia no aumento do número de projetos recebidos das instituições de $\mathrm{P} \& \mathrm{D}$ e do número de projetos selecionados para desenvolvimento, garantindo à Eletronorte a manutenção de um banco de projetos já devidamente priorizados.

Todos os resultados de projetos concluídos são apresentados na Feira Tecnológica, no PIQ, nos fóruns virtuais e em encontros informais dos colaboradores.

Uma exigência legal acabou por impulsionar a empresa na transformação e no aperfeiçoamento de vários processos internos e na consolidação de uma rede de conhecimento e inovação interna e externa, orientada ao desenvolvimento de novas tecnologias.

Nesse contexto, destaca-se a importância dada à criação de uma estrutura formal para cuidar da gestão do conhecimento, incluindo-se aí o Setor de Pesquisa e Desenvolvimento (SPD). O SPD tem, entre suas atividades, a responsabilidade pela importação de conhecimento novo, por meio de projetos de pesquisa e desenvolvimento realizados em parceria com universidades e centros de pesquisa de todo o País.

A criação de um setor específico de $P \& D$ refletiu a necessidade de uma ação estruturada, dirigida por objetivos estratégicos e pressupondo o trabalho conjunto de pessoas de diferentes departamentos e níveis hierárquicos, por meio de comitês.

Em relação aos instrumentos de integração para a disseminação do conhecimento tecnológico, assim como a valorização das iniciativas de compartilhamento desse conhecimento pela Eletronorte, deve-se registrar que, a despeito das dificuldades de levar o conhecimento ao local certo, a empresa vem se preocupando com a ampliação e a realização de treinamentos internos, com incentivos a multiplicadores internos, inclusive em termos de 
remuneração, com a estruturação de comunidades virtuais e presenciais de melhores práticas internas e de fóruns virtuais e presenciais de discussão. Tais práticas buscam aperfeiçoar o processo de gestão do conhecimento.

A sistematização do conhecimento vem sendo realizada pela Eletronorte com a criação de bancos de dados com as competências pessoais, manuais de procedimentos, normas técnicas e páginas amarelas.

A empresa tem buscado soluções para reduzir as dificuldades da transmissão do conhecimento. A criação de um seminário anual, em que as melhores práticas estão sendo divulgadas, tornou-se um importante mecanismo para a disseminação do conhecimento da fonte de criação para o restante da empresa. Movidos por diversos fatores motivacionais, e com o ideal de transformar o seminário em um dos mais importantes momentos para a empresa, os participantes divulgam seus conhecimentos de forma espontânea, porém estruturada.

\section{CONCLUSÃO}

A tendência a gerir o conhecimento por meio de um sistema integrado está levando as empresas a formarem redes de cooperação envolvendo os diversos atores internos e externos, como fornecedores, clientes e instituições de ensino e pesquisa.

Considerando-se que um novo modelo traz impactos positivos sobre o processo de inovação, a preocupação com a disseminação e a transferência do conhecimento tecnológico torna-se o alvo de equipes multidisciplinares que, ao interagirem, acabam por perceber a importância dessa troca de conhecimento, tanto para a sustentabilidade como para a competitividade das empresas.

No estudo de caso realizado, observam-se ações sistemáticas para a disseminação e a aplicação do conhecimento gerado, iniciando-se em 2002 com a promoção da educação e do conhecimento por meio de uma Universidade Corporativa.

A extensão da pesquisa até o ponto de comercialização e a formalização de papéis no processo de inovação são pontos fortes do modelo da empresa em estudo. Além disso, planejamento estratégico, aprendizagem e geração de melhorias e inovação caminham juntos em favor da organização, via processo de gestão de inovação. 
Verificou-se que ações sistemáticas da empresa, como avaliação dos resultados de ciclos anteriores, utilização intensa dos instrumentos de tecnologia da informação, adoção de múltiplas práticas de disseminação e compartilhamento do conhecimento, bem como a concepção de um modelo próprio para gerir a inovação, contribuem para ampliar a capacidade de absorção do conhecimento e fortalecem os esforços em atividades de P\&D.

Em relação às melhorias e inovações introduzidas a partir da aplicação sistemática de práticas de compartilhamento para disseminação e transferência do conhecimento, os resultados foram a integração direta dos vários canais ativos de produção de melhoria e inovação; a redução acentuada do tempo de resposta às áreas que demandam soluções tecnológicas; a triplicação da quantidade de demandas atendidas a cada ciclo, devido à diversidade de canais de atendimento; a redução dos custos de produção da inovação pela avaliação do canal mais adequado para apresentação da solução requerida.

Conclui-se que o processo de disseminação do conhecimento tecnológico na empresa pesquisada encontra-se bem implantado, mas seu sucesso depende ainda de melhor gerenciamento e promoção mais constante de possibilidades de disseminação pelas vias informais, bem como de avaliação mais precisa a partir de indicadores a serem definidos pela empresa.

Além disso, a implantação de redes virtuais entre os colaboradores e os parceiros no desenvolvimento de projetos de $\mathrm{P} \& \mathrm{D}$ certamente deverá contribuir para a transferência do conhecimento na empresa.

A exigência legal que obriga as concessionárias de energia elétrica a investirem em pesquisa e desenvolvimento tecnológico tem exigido dessas empresas a adequação de suas estratégias, especialmente no que se refere à gestão tecnológica, visando aperfeiçoar a aplicação dos recursos a serem investidos em P\&D. Por sua vez, os trabalhadores têm aumentado significativamente seus níveis de educação e aspirações, podendo-se inferir que este é um bom momento para criar círculos virtuosos de geração de conhecimentos, com as empresas se reinventando, desenvolvendo competências, aprendendo com o ambiente, adotando estruturas e processos que atendam a todos, tanto em nível organizacional quanto individual.

Finalmente, para que as empresas do setor elétrico possam utilizar o conhecimento tecnológico gerado em seus projetos de $\mathrm{P} \& \mathrm{D}$, sugere-se, a partir da literatura e do caso estudado, além da divulgação sistemática dos registros formais, a exemplo dos relatórios técnicos e manuais, a criação de blogs temáticos ou setoriais, o estabelecimento de 
comunidades de prática envolvendo as universidades e centros de pesquisa desenvolvedores dos projetos, reuniões informais para troca de informações e especialmente a criação de uma rede relacional de forma a viabilizar a conversão do conhecimento tácito dos participantes da rede em conhecimento tecnológico, registrado e utilizado em prol da competitividade das empresas.

\section{Referências}

ANEEL. AGÊNCIA NACIONAL DE ENERGIA ELÉTRICA (Brasil). Manual do Programa de Pesquisa e Desenvolvimento Tecnológico do setor de energia elétrica. Brasília: Aneel, 2001.

ANGELONI, M. T. Organizações do conhecimento: infraestrutura, pessoas e tecnologias. São Paulo: Saraiva, 1999.

DAVENPORT, T. H.; PRUSAK, L. Conhecimento empresarial: como as organizações gerenciam o seu capital intelectual. Rio de Janeiro: Campus, 1999.

FAULKNER, W. Conceptualizing knowledge used in innovation: a second look at the science-technology distinction and industrial innovation. Science Technology and Human Value, v. 19, n. 4, p. 425-458, 1994.

FLEURY, M. T. L.; OLIVEIRA JR., M. M. Gestão Estratégica do Conhecimento. São Paulo: Atlas, 2001.

GRANT, E.; STEELE, A. International manufacturing transfer: linking context and process. ICAM'95: Anthropocentric Lean Production System. Proceedings... Sunderland (UK), p. 1113, set. 1995.

NONAKA, I.; TAKEUCHI, H. Criação de conhecimento na empresa. Rio de Janeiro: Campus, 1997.

PLONSKI, G. A. Novas alianças e parcerias em ciência, tecnologia e engenharia: a cooperação universidade-indústria. In: XV Simpósio Nacional de Pesquisa em Administração em Ciência e Tecnologia... Anais... USP, São Paulo, 1990.

REBENTISH, E. S.; FERRETI, M. A knowledge asset-based view of technology transfer in international joint ventures. Working paper 86-93. Cambridge, Mass.: Sloan School of Management, MIT, 1993. 
SANDIA NATIONAL LABORATORIES. A strong science, technology, and engineering heritage extends into the future. Sandia's Annual Report, 1999. Disponível em: http://www.sandia.gov/mission/ste/index.html> Acesso em: 15 mar. 2008.

SPENCE, W. R. Innovation: the communication of change in ideas, practices and products. London: Chapman \& Hall, 1994. 